\title{
Thermomechanical Analysis on Ti-Ni Shape Memory Helical Springs Under Cyclic Tensile Loads
}

\author{
Carlos Augusto do Nascimento Oliveira ${ }^{a *}$, Cezar Henrique Gonzalez ${ }^{a}$, Oscar Olimpio Filho ${ }^{a}$, \\ Niédson José da Silva ${ }^{b}$, Pablo Batista Guimarães ${ }^{b}$, Esau Nuñez-Mendozac, \\ Enrique Manuel López Cuéllar \\ ${ }^{a}$ Universidade Federal de Pernambuco - UFPE, Av. Prof. Moraes Rego, 1235, \\ Cidade Universitária, CEP 50670-901, Recife, PE, Brasil \\ ${ }^{b}$ Instituto Federal de Pernambuco - IFPE, Estrada do Alto do Moura, Km 3.8, \\ Industrial District III, CEP 55040-120, Caruaru, PE, Brasil \\ ${ }^{c}$ Universidad Autónoma de Nuevo León, Pedro de Alba, s/n, \\ San Nicolás de Los Garza, Nuevo León, Mexico
}

Received: September 30, 2014; Revised: November 11, 2015

\begin{abstract}
Shape memory alloys (SMAs) present some characteristics, which make it unique material to be use in applications that require strength and shape recovery. This alloys was been used to manufacture smart actuators for mechanical industry devices and several other applications in areas as medicine, robotics, aerospace, petroleum and gas industries. However it is important to know the actuators response to external stimulus (heat source, electrical current and/or external stress) in these technological applications. This work investigated the thermomechanical behaviors of helical actuators produced from Ti-Ni alloy commercial wires. Initially, the wire was subjected to some heat treatment and characterized by differential scanning calorimeter (DSC), scanning electron microscopy (SEM), optical microscopy (OM) and Energy dispersive spectroscopy. Then two heat treatments were selected to obtain the helical actuators. The actuators were tested in an apparatus developed to apply an external traction stress in helical actuators during thermal cycles. Two wires were tested in a dynamic mechanical analyzer (DMA). The results were analyzed in comparison with thermoplastic properties obtained in thermomechanical tests. The analysis took into consideration the wiring forming process, the precipitates formation, the stress fields generated by dislocations and reorientation of martensite variants during the actuators training process.
\end{abstract}

Keywords: shape memory alloys, Ti-Ni alloys, heat treatment, r-phase transformation, thermoelastic properties

\section{Introduction}

Recently, many studies is being developed in the materials field with the aim to understand the transformation phenomena which involving shape memory smart materials. These materials present phase transformations that allow the research and development of actuator/sensor elements. Mechanical properties of Ti-Ni alloys are very interesting for developing smart actuators manufactured from these non-conventional materials. In many technological applications these actuators need to generate force and to avoid the degradation of the shape memory effect caused by the martensitic stabilization processes $^{1,2}$. Shape memory phenomena and mechanical properties of the alloys may induce adequate conditions to obtain sensors/actuators capable to produce mechanical work to be used in several industrial applications such as: medicine, robotics, aerospace, petroleum and gas. Several shapes might be used to obtain smart sensors/actuators, however helical spring shapes are more interesting because

*e-mail: cano.oliveira@gmail.com of its characteristics of deflection, power generation and elastic constant ${ }^{3}$.

This research was developed as a mechanical and metallurgical study of commercial wires with a composition of Ti-50.4at $\% \mathrm{Ni}$. Several heat treatments were investigated in order to modify the critical transformation temperatures. The objectives were to shift the critical temperatures to values close to room temperature. These heat treatments can promote the presence of the $\mathrm{R}$ phase. This phase appears by several factors, which include the chemical composition of Ti-Ni and metal forming processes.

Despite several studies to understanding the R-phase formation in the Ti-Ni alloys, some applications could use the narrow ranges of shape recovery presented by this phase. Several researches indicate that the presence of the $\mathrm{R}$-phase during the martensitic transformation hardens the matrix phase (two-steps, B2 $\rightarrow \mathrm{R} \rightarrow \mathrm{B} 19^{\prime}$, where B2 and B19' represent crystalline structures of the austenitic and martensitic phases, respectively). This hardening hinders 
the generation of stress fields that are associated with the dislocation reconfiguration processes. The presence of these stress fields promotes the Two Way Shape Memory Effect (TWSME) ${ }^{4,5}$. Study of thermoelasticity in shape memory springs will allow understanding the behaviors of austenitic and martensitic phases with external loadings.

Initially, the wire was subjected to some heat treatment and characterized by differential scanning calorimeter (DSC), scanning electron microscopy (SEM), optical microscopy (OM) and Energy dispersive spectroscopy. Then two heat treatments were selected to obtain the helical actuators. The actuators were tested in an apparatus developed to apply an external traction stress in helical actuators during thermal cycles. Two wires were tested in a dynamic mechanical analyzer (DMA).

\section{Experimental Procedure}

A cold-drawn wire of shape memory alloy (SMA) with chemical composition of Ti-50.4at $\% \mathrm{Ni}$ and $0.89 \mathrm{~mm}$ diameter was used to manufacture a helical spring actuator.

Initially, wire samples were subjected to heat treatment to observe the behavior of the martensitic transformation critical temperatures (martensite start- $\mathrm{M}_{\mathrm{s}}$, martensite finish- $\mathrm{M}_{\mathrm{f}}$, austenite start- $\mathrm{A}_{\mathrm{s}}$, austenite finish- $\mathrm{A}_{\mathrm{f}}$, rhombohedral start or R-phase start- $\mathrm{R}_{\mathrm{s}}$ and R-phase finish- $\mathrm{R}_{\mathrm{f}}$ ). These critical temperatures were determined by differential scanning calorimetry (DSC). Thermal cycles were carried out in a range between $-60{ }^{\circ} \mathrm{C}$ and $90{ }^{\circ} \mathrm{C}$ at a constant rate of $10{ }^{\circ} \mathrm{C} \cdot \min -1\left(\right.$ Mettler calorimeter, model $\left.823^{\mathrm{e}}\right)$. Samples were homogenized in advance in a furnace at $400{ }^{\circ} \mathrm{C}(\mathrm{HT} 1)$ and $500^{\circ} \mathrm{C}$ (HT2) for time of $1,2,4,8,12$ and 24 hours, followed by quenching in water at $25^{\circ} \mathrm{C}$.

Two helical actuators were obtained by plastic deformation of the wire around a screw. Then, an assembly (wire/screw) was subjected to heat treatment at $400{ }^{\circ} \mathrm{C}$ for 24 hours, and then quenched in water at room temperature. The other set was treated at $500{ }^{\circ} \mathrm{C}$. This process resulted in shape memory spring with outer diameter of $6.0 \mathrm{~mm}, 6.0 \mathrm{~mm}$ long and 4 active coils.

The internal stress and damping capacity was conducted in a dynamical mechanical analysis (DMA) system of the DMA Q800 da TA Instruments. The samples were submitted to a single cantilever fixation and a heating process was developed from $20^{\circ} \mathrm{C}$ to $170{ }^{\circ} \mathrm{C}$ with rate of $5^{\circ} \mathrm{C} \cdot \mathrm{min}^{-1}$. Frequency and amplitude oscillation used were of $1 \mathrm{~Hz}$ and $5 \mu \mathrm{m}$, respectively.

The microstructure of the material was analyzed in order to identify precipitation and to visualize the martensitic variants. Scanning electron microscopy and energy dispersive spectroscopy were carried out to analyze samples submitted to HT1 and HT2 treatments. Samples were cold-mounted by a resin compound. Metallographic samples were sanded with sandpapers and then polished with aqueous solutions of alumina particles with size of 1 and $0.5 \mathrm{~mm}$. The samples were attacked with $\mathrm{HF}-\mathrm{HNO}_{3}-\mathrm{CH}_{3} \mathrm{COOH}$ (acide fluorrhydrique-acide nitrique-acide acétique) in the ratio of 2:5:5, for periods of 1 or 2 seconds.

Shape memory springs (SMS) were thermomechanically tested in a loading special apparatus. This device is constituted of a programmable silicon oil bath, a linear variation displacement transducer (LVDT), thermocouples and a computational data acquisition system. SMS were submitted to 40 thermal cycles under constant shear stress of 35,70 , $105,135,170,200,235$ and $270 \mathrm{MPa}$ in a temperature interval between 25 and $140{ }^{\circ} \mathrm{C}$. The heating and cooling rate was estimated in 10 and $4^{\circ} \mathrm{C} \cdot \mathrm{min}^{-1}$, respectively $\mathrm{y}^{4,6,7}$.

From data acquisitions, the curves of deformation versus temperature and temperature versus number of cycles were plotted. Figure 1 shows a typical graph obtained during thermomechanical cycling, as well as, the determination critical transformation temperatures under stress, by using of the tangent method, thermoelastic strains $\left(\varepsilon_{t}=\right.$ difference between the largest and smallest displacement of LVDT), thermal hysteresis $\left(\mathrm{H}_{\mathrm{T}}\right)$ and vertical shifts of hysteresis loops $(\mathrm{X})^{4,6}$.

\section{Results}

\subsection{Influence of heat treatment on phase transformations}

Figure $2 \mathrm{a}$ shows the curve of heat flux in function of temperature obtained by the DSC in a Ni-Ti wire sample in as-received conditions. DSC results do not shows any signal of transformation peaks for direct and inverse transformation. This can be explained from the plastic forming process to which the material was submitted (wire drawing process). During this process are introduced a large concentration of linear crystalline defects (dislocations). This large concentration of defects acts as an obstacle the occurrence of phase transformation through blocking of all variants of martensite $\mathrm{s}^{4,5,8,9}$.

The calorimetric curves for the samples treated at $400{ }^{\circ} \mathrm{C}$ (HT1-24h) and $500{ }^{\circ} \mathrm{C}$ (HT2-24) for 24 hours are shown in Figure $2 \mathrm{~b}$, c. Table 1 shows the results of the calorimetric analysis of the samples treated at $400{ }^{\circ} \mathrm{C}$ and $500{ }^{\circ} \mathrm{C}$ for times of 1, 2, 4, 8, 12 and 24 hours.

Calorimetric analyzes show that heat treatments promoted changes in the martensitic transformation and changed their critical temperatures. All samples heat treated at $400{ }^{\circ} \mathrm{C}$ exhibit a transformation in two steps $\left(\mathrm{B} 2 \rightarrow \mathrm{R} \rightarrow \mathrm{B} 19^{\prime}\right)$ for all annealing periods. According to studies, two steps transformation occurs due to the formation of nickel-rich

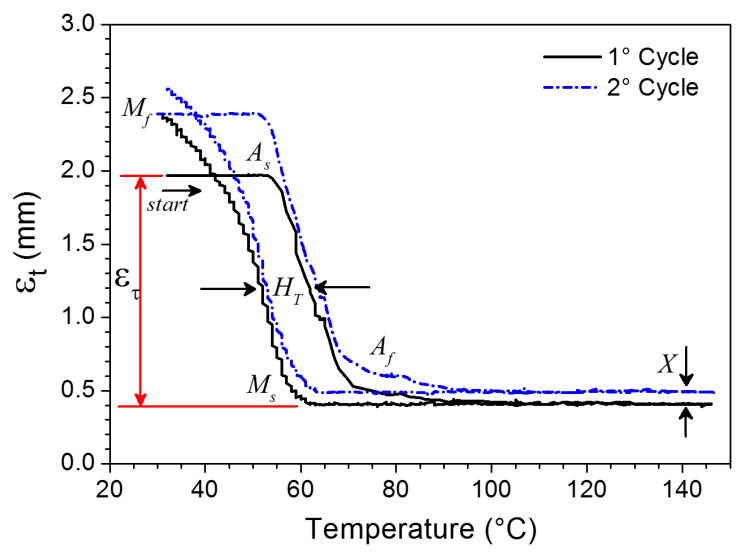

Figure 1. The typical curves of thermoelastic strain versus temperature and determination of thermoelastic properties. 


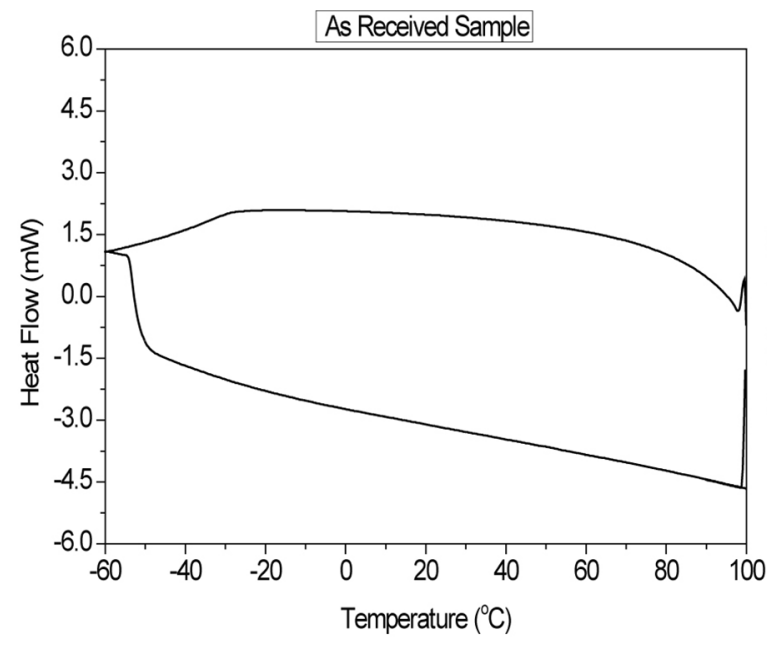

(a)

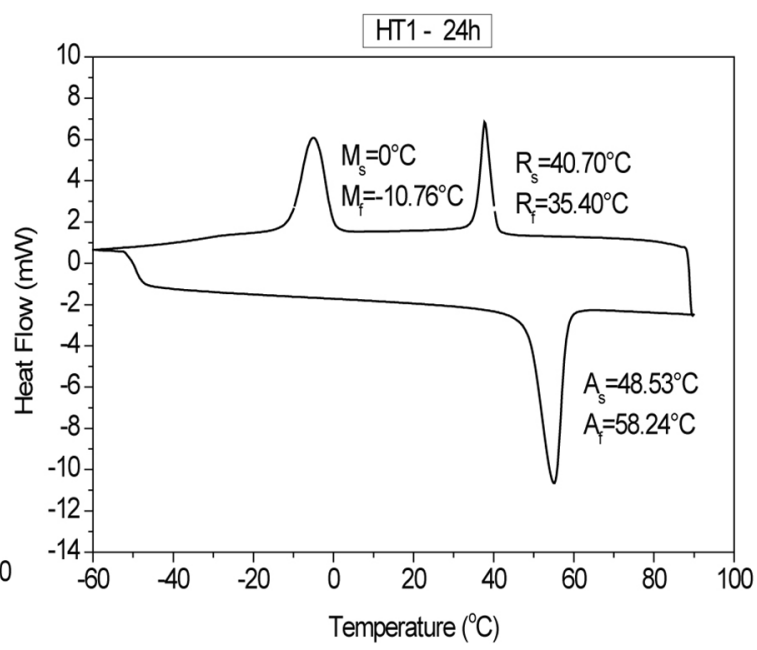

(b)

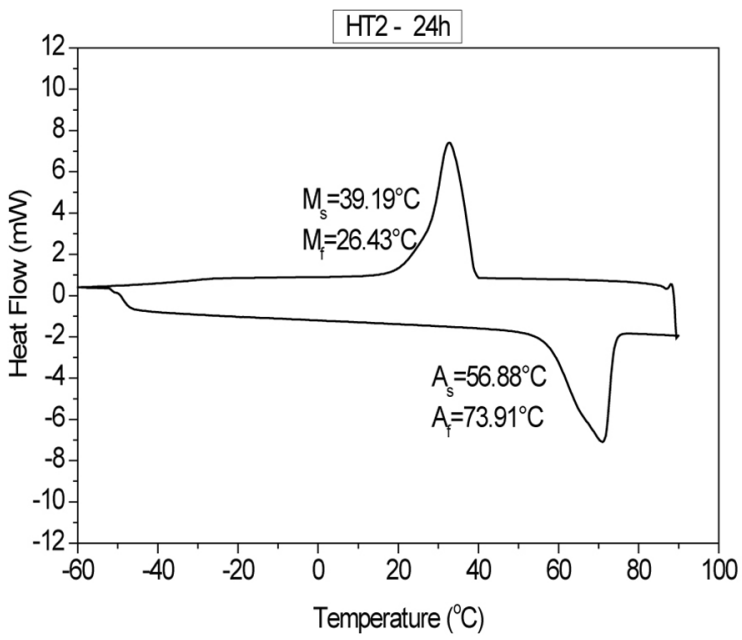

(c)

Figure 2. Calorimetric curves of samples: (a) as-received condition, (b) HT1-24h and (c) HT2-24h.

Table 1. Summary of results of the calorimetric properties of the samples treated at $400{ }^{\circ} \mathrm{C}$ and $500{ }^{\circ} \mathrm{C}$.

\begin{tabular}{|c|c|c|c|c|c|c|c|c|c|}
\hline \multirow{2}{*}{ Time (h) } & \multicolumn{9}{|c|}{ HT1 } \\
\hline & As & Af & $\Delta \mathbf{H}(\mathbf{J} / \mathbf{g})$ & Ms & Mf & $\Delta \mathbf{H}(\mathrm{J} / \mathrm{g})$ & Rs & $\mathbf{R f}$ & $\Delta \mathbf{H}(\mathrm{J} / \mathrm{g})$ \\
\hline 1 & 33.84 & 42.95 & 20.56 & -22.17 & -38.77 & 12.30 & 33.30 & 25.65 & 6.59 \\
\hline 2 & 40.25 & 50.21 & 21.90 & -14.30 & -30.83 & 14.81 & 35.31 & 28.93 & 7.05 \\
\hline 4 & 44.10 & 59.56 & 19.69 & -12.44 & -33.72 & 13.33 & 38.15 & 27.89 & 7.38 \\
\hline 8 & 45.23 & 55.17 & 22.88 & -7.22 & -19.97 & 14.48 & 40.22 & 34.83 & 8.70 \\
\hline 12 & 46.76 & 56.67 & 22.54 & -4.18 & -16.27 & 14.14 & 40.23 & 34.65 & 7.75 \\
\hline 24 & 48.53 & 58.24 & 21.03 & 0.06 & -10.76 & 12.16 & 40.70 & 35.40 & 7.10 \\
\hline \multirow{2}{*}{ Time (h) } & \multicolumn{9}{|c|}{ HT2 } \\
\hline & As & Af & $\Delta \mathbf{H}(\mathrm{J} / \mathrm{g})$ & Ms & Mf & $\Delta \mathbf{H}(\mathrm{J} / \mathrm{g})$ & Rs & $\mathbf{R f}$ & $\Delta \mathbf{H}(\mathrm{J} / \mathrm{g})$ \\
\hline 1 & 16.69 & 27.28 & 20.31 & -23.89 & -35.92 & 13.96 & 8.43 & 2.65 & 4.99 \\
\hline 2 & 19.15 & 31.27 & 22.16 & -16.80 & -32.15 & 16.82 & 9.45 & 2.89 & 5.91 \\
\hline 4 & 23.07 & 36.26 & 19.82 & -6.59 & -24.78 & 12.43 & 12.55 & 6.10 & 4.32 \\
\hline 8 & 26.07 & 43.53 & 22.41 & 1.45 & -19.50 & 18.42 & 15.00 & 8.40 & 7.79 \\
\hline 12 & 36.00 & 64.31 & 24.84 & 33.54 & 2.80 & 26.06 & $\mathrm{x}$ & $\mathrm{x}$ & $\mathrm{x}$ \\
\hline 24 & 56.88 & 73.91 & 24.81 & 39.19 & 26.43 & 25.99 & $\mathrm{x}$ & $\mathrm{x}$ & $\mathrm{x}$ \\
\hline
\end{tabular}


precipitates during heat treatment in the matrix phase $\mathrm{e}^{10,11}$. Temperatures were dislocated in the sense of increasing the critical transformation temperature. Annealed samples at $400{ }^{\circ} \mathrm{C}$ showed $\mathrm{A}_{\mathrm{s}}$ variation from $33.8^{\circ} \mathrm{C}$ for 1 hour to $48.5^{\circ} \mathrm{C}$ for 24 hour ageing. $\mathrm{M}_{\mathrm{s}}$ showed variation from $-21.2^{\circ} \mathrm{C}$ for 1 hour to $0^{\circ} \mathrm{C}$ for 24 hours ageing.

Samples heat treated at $500{ }^{\circ} \mathrm{C}$ showed two-step sequence: austenite, R-phase and martensite, indicating a trend of reduction between the peaks of the R-phase and martensite. In the test of sample aged for 12 hours shown that R-phase practically disappears, but present a single peak with large hysteresis thermal.

The modification observed on DSC results, where temperature and transformation phases are involved, this changes have been investigated in the literature and two main causes are reported: near-equiatomic Ti-Ni SMA lightly rich in nickel can form precipitates during heat treatment at high temperatures, such as $\mathrm{Ti}_{3} \mathrm{Ni}_{4}, \mathrm{Ti}_{2} \mathrm{Ni}_{3}$ and $\mathrm{TiNi}_{3}^{8,10,12}$. These precipitates have influence on MT (martensitic transformation) because act as preferential sites for nucleation reaction, inhibiting and/or suppressing the appearance of R-phase. Precipitation occurs from diffusional processes which involve changes in local chemical composition, modifying transformation temperatures in such a way that increase of $M_{s}$ transformation temperature ${ }^{7,13-16}$. A second important factor is about deformation stage or dislocation density configurations. This factor depends mainly of the material processing method, thermomechanical heat treatments and others. The wires used in this work were obtained by a cold-drawn process that results in a material with high dislocation density. Normally, alloys with high dislocation density show two transformation peaks during cooling which corresponding R and B19' phases ${ }^{4,16,17}$.

\subsection{Microstructural investigation}

Figure 3 shows images of optical and electronic scanning micrographs for heat-treated samples with HT1-24 h and HT2-24 h. The electronic microscopy were carried out on the square dashed and are shown in the larger rectangle in the upper right side (darker). Acicular structures similar to martensitic variants can be visualized. The images revealed morphological distinction between them. Figure 3 a shows a high number of well-defined acicular structures with different orientation. Compared to samples heat treated at HT1, samples subjected at HT2 shows less acicular form and larger grains due to a higher heat treatment temperature. According to literature $M_{s}$ transformation temperature increase with the increasing of grain size ${ }^{18,19}$.

Figure 4 shows energy dispersive spectroscopy (EDS) results for samples submitted to HT1-24h and HT2-24h. EDS was realized in a small region of the samples. Both samples show peaks of Ti and Ni elements. Results indicate in a qualitative way that the samples studied are Ni-rich. This technique is not suitable, but the results are consistent with the Ni-Ti wire manufacturer's information.

\subsection{Thermomechanical analysis}

Thermomechanical heat treatment process were performed in thermal silicone oil bath, known in literature as a training process $^{20}$. The apparatus used for this work, was able to developing the heating and cooling on the actuators, which consequently induced phase transformation in the samples. A constant shear stress was applied in the actuator in order to induce martensite variants in a preferential direction in relation with the applied stress. During the process the training leads formation of preferential variants who induces shape modification and changes on the transformation temperatures ${ }^{21}$.

The obtained graphs from training process allowed the studied on several shape memory effect parameter modifications (transformation temperatures, thermal hysteresis and thermoelastic strain (Et)). Thermal hysteresis and thermoelastic strain are also important parameters on the actuators behavior. Thermoelastic parameters are capable to indicate the shape memory efficiency as a function of the linear displacement. Figure 5 shows curves of thermoelastic effect versus temperature during forty cycles for tensile stress of 105MPa for HT1-24 and HT2-24 heat treatments.

Among the most important information obtained during the training process, it was observed the strain variation due to temperature, the vertical displacement on hysteresis loops, the increasing on the thermoelastic strain $\left(E_{t}\right)$ caused by stress increment, besides of the double "s" observed during cooling

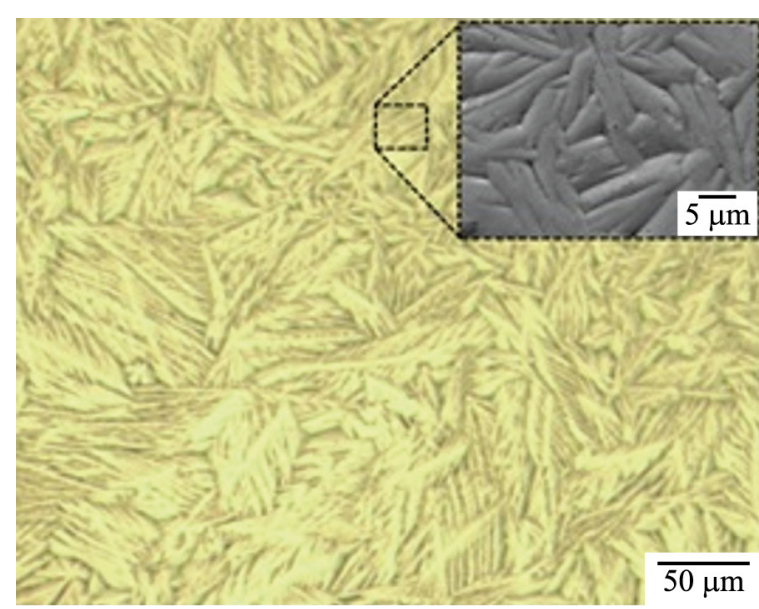

(a)

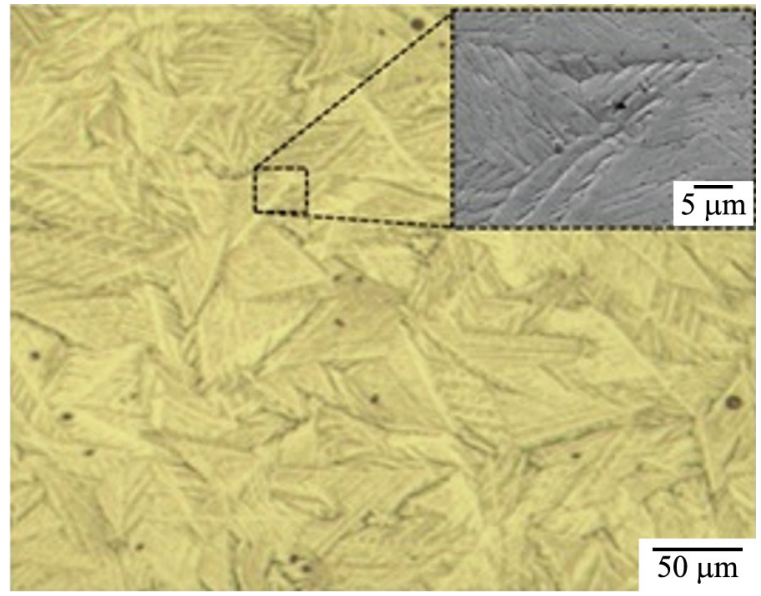

(b)

Figure 3. Optical and electronic scanning microscopy, samples: (a) HT1-24h and (b) HT2-24h. 
on samples heat treated at HT1-24. The vertical displacement on hysteresis loops might be attributed to transformation induced plastically (TRIP) due to accumulation of small plastic strain ${ }^{22,23}$. Other factors also may contribute, as for example: spring actuator displacement due to rotation, martensitic stabilization process and martensitic variants reorientation ${ }^{6}$.

Figure 6 shows thermoelastic strain $\left(E_{t}\right)$ versus number of cycles curves for each applied shear stress. Initially, thermoelastic strains show an increase according with stress

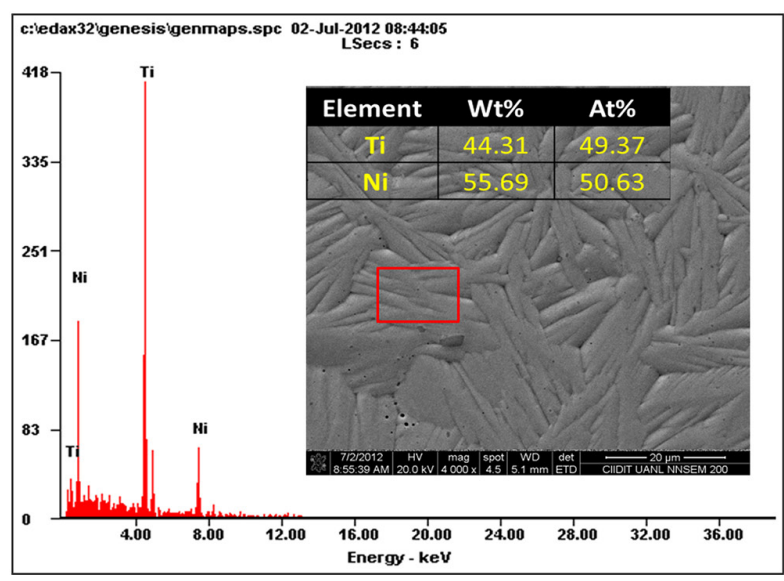

(a)

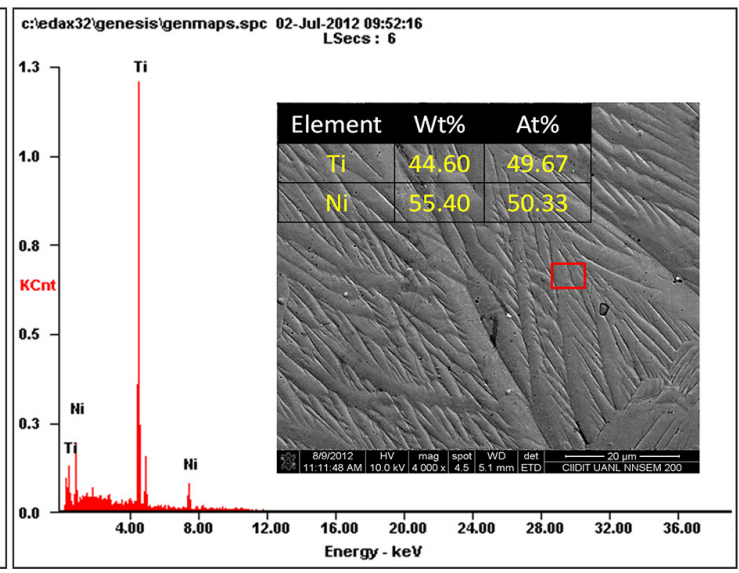

(b)

Figure 4. Energy dispersive spectroscopy (EDS) results for samples submitted to (a) HT1-24h and (b) HT2-24h.

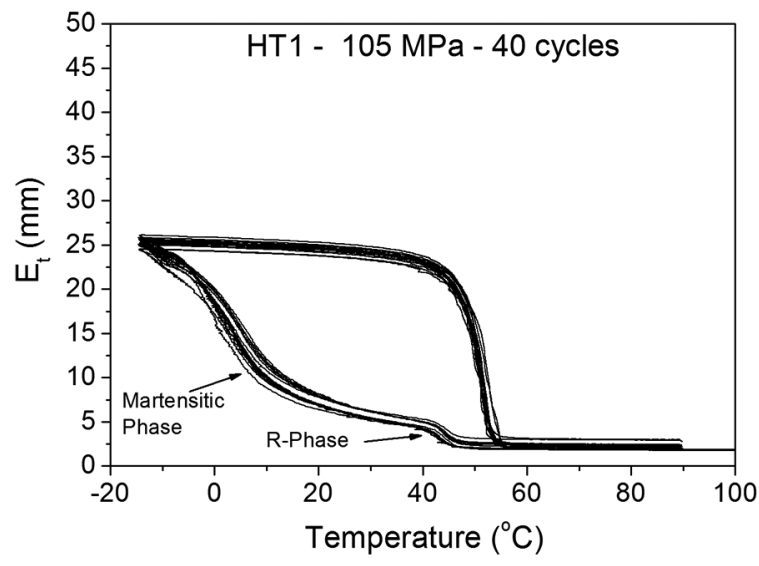

(a)

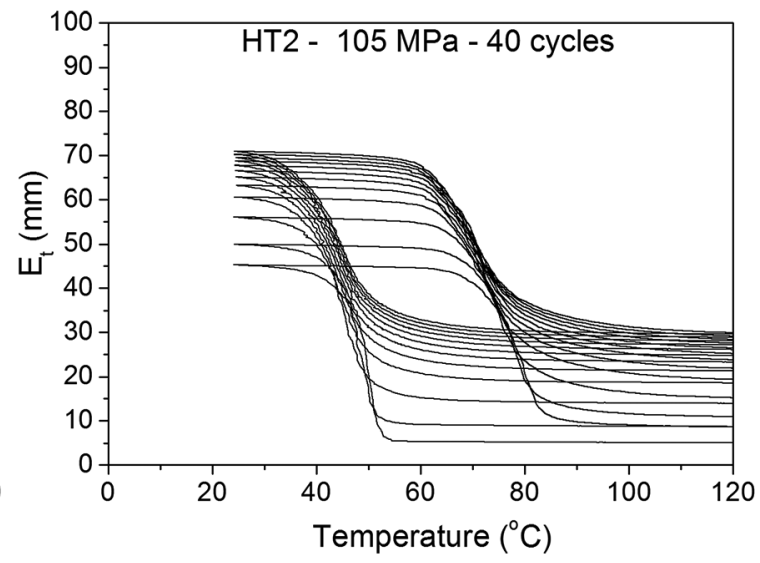

(b)

Figure 5. Thermoelastic strain versus temperature curves for tensile stress of $105 \mathrm{MPa}$, for samples: (a) HT1-24h and (b) HT2-24h.

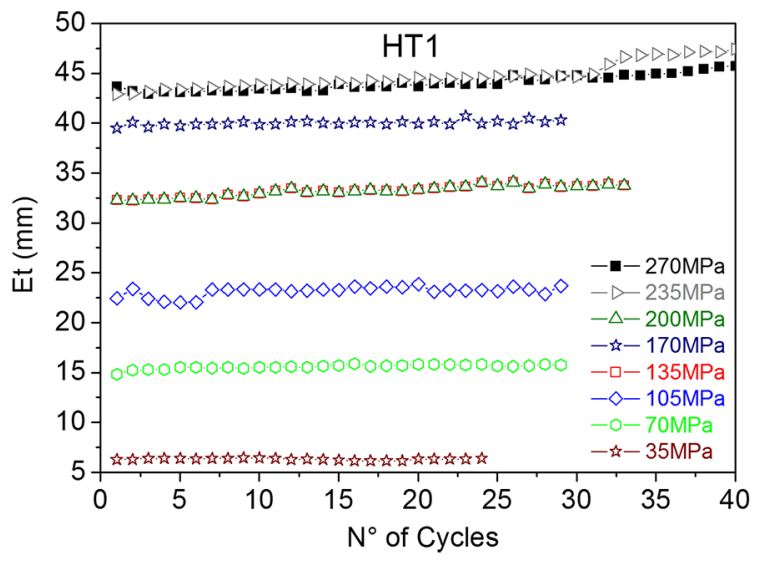

(a)

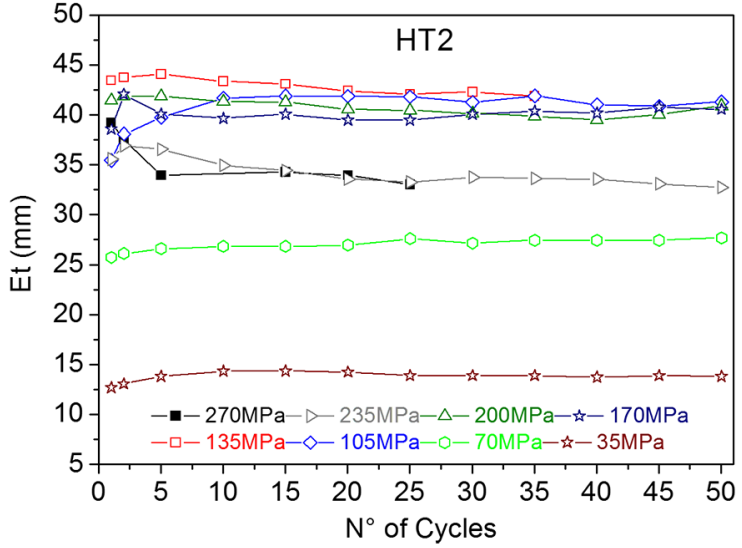

(b)

Figure 6. Thermoelastic strain versus number of cycles for 35, 70, 105, 135, 170, 200, 235 and 270 MPa stress. (a) HT1-24h and (b) HT2-24h. 
increments, but their evolutions for each heat treatment during training cycles exhibit same differences.

Evaluating samples submitted to HT1-24 it was observed that for 70 and $105 \mathrm{MPa}$ a gradual increase during training cycles until practically strain stabilization for the last cycles. It was also observed for results obtained with stress of $200 \mathrm{MPa}$ a sharp fall on thermoelastic strain to levels near the obtained for $135 \mathrm{MPa}$. It is possible that this particular stress might be involved with R-phase transformation suppression. In this case $(200 \mathrm{MPa})$ it was observed during experimental procedure that the two steps transformation $\left(\mathrm{B} 2 \rightarrow \mathrm{R} \rightarrow \mathrm{B} 19^{\prime}\right)$ starts to be replaced by one step transformation $\left(\mathrm{B} 2 \rightarrow \mathrm{B} 19^{\prime}\right)^{12}$.

During the training process occurs martensitic variants reorientation where internal stresses generated by dislocation fields becoming preferential according to stress direction ${ }^{20}$. For low and intermediate stresses, internal stress fields are formed gradually in each cycle, increasing thermoelastic strain during training. In this sense, 105 and $135 \mathrm{MPa}$ stress present the best results in comparison with tests developed, whereas 170 and $200 \mathrm{MPa}$ stress produce a decrease of the thermoelastic strain due to the rapidly saturation of internal stress fields. These behaviors have been observed in cooper based shape memory alloy springs ${ }^{5}$.

Actuators heat treated with HT2-24 also exhibit an increase on the thermoelastic strain with stress increments; however, for low levels of stress, the actuators produced a better efficiency on the SME comparing to HT1-24 results. Stress of 105, 135, 170 and $200 \mathrm{MPa}$ present almost the same thermoelastic strain near $40.0 \mathrm{~mm}$ (see Figure 5). The main difference from HT1-24 results is that for 235 and $270 \mathrm{MPa}$, the actuators exhibit a better SME. The main results suggest that due to R-phase transformation mechanism and the developing of preferential variants orientation for samples heat treated at HT1-24h has a better SME efficiency ${ }^{24}$.

The efficiency of the TWSME might be evaluated by temperature transformation evolution. Figure 7 shows the evolution of $\left(\mathrm{M}_{\mathrm{s}}\right)$ for both heat treatments. Samples heat treated with HT1-24 shows for all studied situations an increase on transformation temperature when increasing cycles and stress, and a more homogeneous temperatures evolution. The actuators obtained used from samples heat treated at HT2-24 showed higher values of $\mathrm{M}_{\mathrm{s}}$ and a high level of permanent deformation for 235 and $270 \mathrm{MPa}$ which did not allow the continuity of the test for those conditions.

\subsection{Training Process versus Internal Friction}

It was already observed that internal friction in near equiatomic Ti-Ni alloys is related to stress fields for martensite reorientation. These fields are strongly related with the annealing temperature and their interaction with other lattice defects $^{25}$. Heat treatment and training process seriously affects the internal friction behavior in Ti-Ni alloys ${ }^{26,27,28}$. These events have an importance on the reconfiguration of Ti-Ni alloy defects, inducing modification that might change the material properties such as memory effect, damping capacity, strength, hardness, and others ${ }^{26,27,28}$. Martensitic transformations are associated to the shear stress direction applied during the procedure. According to studies $\mathrm{Ni} / \mathrm{Ti}$ ratio has influence on internal stress degree in the parent and martensite phases ${ }^{26}$. Internal defects propagation hinders the movement of martensite-austenite interface, inducing thermoelastic transformation to require more energy to overcome internal stress between phases. The increase on transformation energy can be visualized on the $\mathrm{M}_{\mathrm{s}}$ behavior, which increases with increasing applied stress and number of cycles (Figure 7) ${ }^{6,20}$. Figure 8 shows internal friction $(\tan \delta$ ) (Figure 8a) and storage modulus (Figure 8b) as function of temperatures during cooling step by DMA technique. Figure 8a indicates that the peak temperature for austenite to R-phase and R-phase to martensite transformation occur at $115^{\circ} \mathrm{C}$ and $73{ }^{\circ} \mathrm{C}$, respectively for HT1-24 heat treatment. Figure $8 \mathrm{~b}$ indicates austenitic transformation to occur at $100{ }^{\circ} \mathrm{C}$ for HT2-24. Figure 8 also exhibit a high level of internal friction on samples submitted to HT1-24 where internal friction reaches $0.1528(\tan \delta)$. Same studies developed a relation between R-phase transformation and damping capacity where the occurrences of R-phase significantly soften the storage modulus and thus increase the internal friction ${ }^{29-31}$. Samples heat treated with HT1-24 exhibit a higher internal friction, compared with HT2-24.

Figure 9 shows $M_{\mathrm{s}}$ versus stress for $1,5,10,15,20$ and 25 cycles. For both heat treatments $M_{\mathrm{s}}$ increase when stress

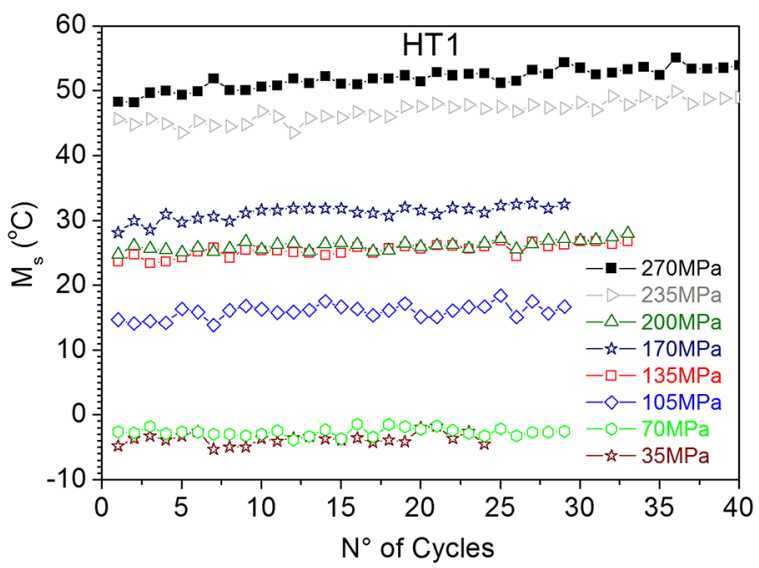

(a)

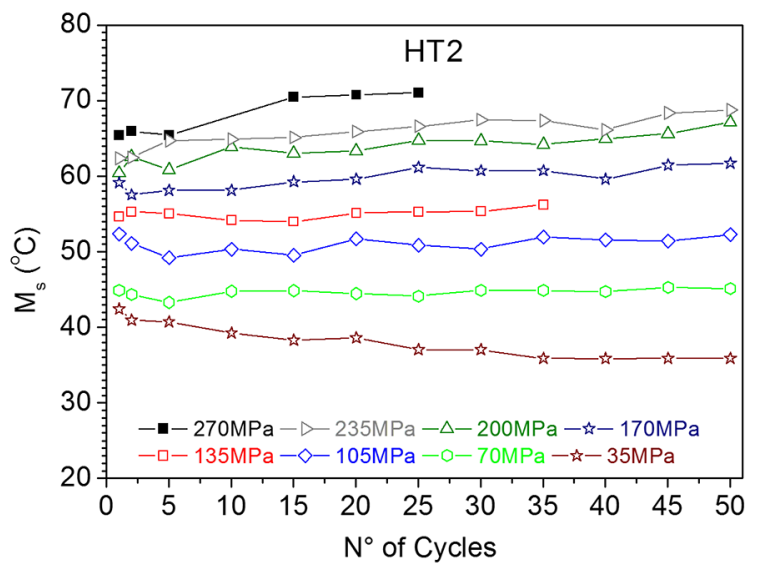

(b)

Figure 7. Evolutions of the Ms versus number cycles for 35, 70, 105, 135, 170, 200, 235 and 270 MPa applied stresses: (a) HT1 and (b) HT2. 


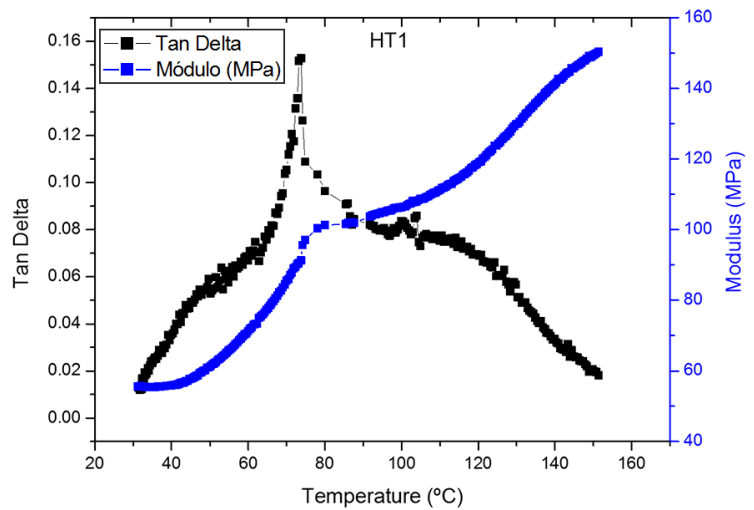

(a)

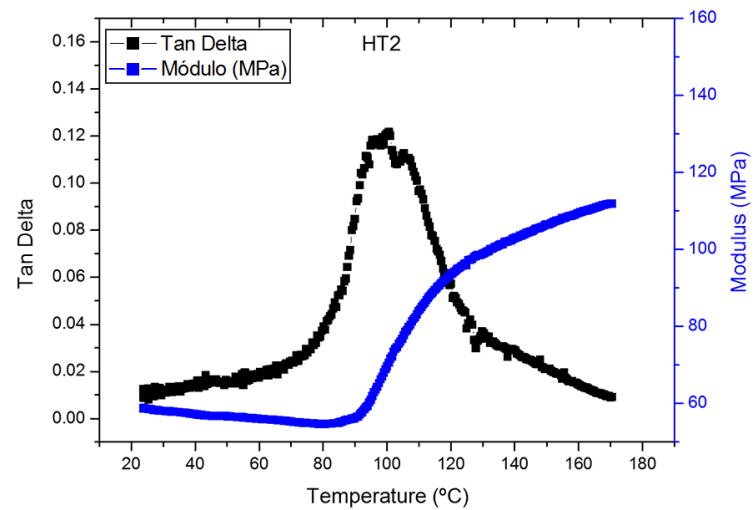

(b)

Figure 8. Internal friction $\tan \delta$ and storage modulus as a function of temperature during step cooling for Ti-Ni alloy by DMA.

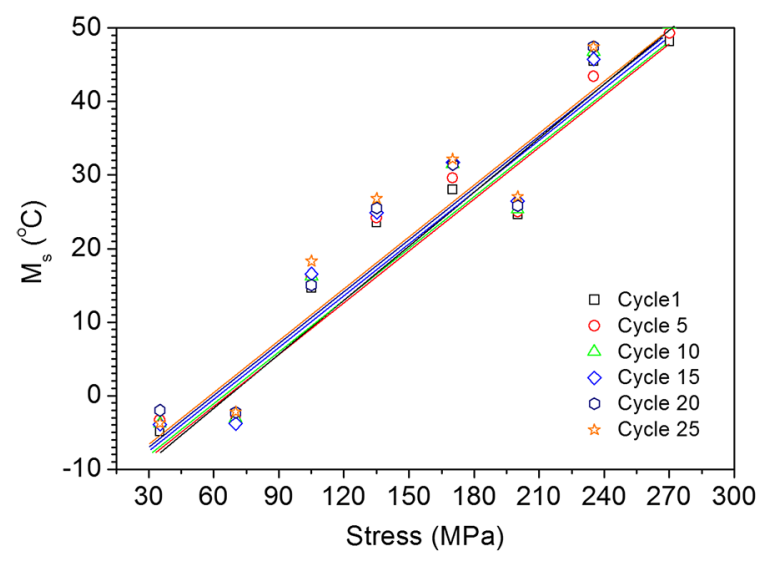

(a)

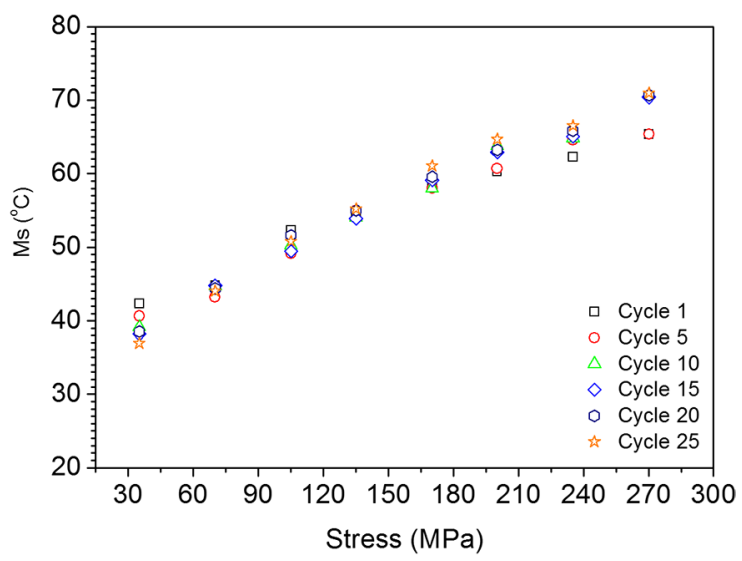

(b)

Figure 9. Variations in Ms temperatures due to the stress applied during the thermomechanical cycles.

increase. For samples heat treated at HT1-24 (Figure 9a) was detected two points under the linear fit. These points refer to stress of 70 and $200 \mathrm{MPa}$, exactly the same values who exhibit a fall on thermoelastic strain (200 MPa - Figure 7). Changes observed for $200 \mathrm{MPa}$ might be due to interaction of stress fields on martensitic and R-phase during training process.

Figure 9b shows samples heat treated at HT2-24 where $\mathrm{M}_{\mathrm{s}}$ for $35 \mathrm{MPa}$ has been reduce when the number of cycles is increasing. For stress between 70 and $170 \mathrm{MPa}$, the $\mathrm{M}_{\mathrm{s}}$ exhibits a very narrow variation, being this temperature parameter very close for different cycles. For stress between 200 and $270 \mathrm{MPa}, \mathrm{M}_{\mathrm{s}}$ becomes very wide for increments with the number of cycles.

\section{Conclusions}

In this work we found that heat treatments cause in Ti-Ni alloys, slightly rich in nickel, an increase in critical transformation temperature. In the case of heat treatment at $500{ }^{\circ} \mathrm{C}$ (HT2-24), the R phase was apparently removed. In colorimetric tests thermal hysteresis shows a small increase of about $4{ }^{\circ} \mathrm{C}$ compared to the other treatments $\left(\mathrm{A}_{\mathrm{s}}-\mathrm{M}_{\mathrm{s}}=14^{\circ} \mathrm{C}\right)$. In thermomechanical cycles test hysteresis loop was about $32^{\circ} \mathrm{C}$, which is much lower than samples with 1-24 HT treatment that exhibit hysteresis of about $50^{\circ} \mathrm{C}$ due to the two steps transformation.

Internal friction shows that the HT1 treatment leaves samples more resistant. This fact can be verified by thermomechanical cycles tests. Probably the HT2 treatment promotes reduce on stress fields (dislocation), allowing greater thermoelastic deformations for small loads. HT1 treatment actuators have more strength and can be used for larger loads. However, there is a load limit. In this work we found for HT1 treatment, for $200 \mathrm{MPa}$ a drop in thermoelasticity that should be related to interaction between the martensitic and rhombohedral transformations.

\section{Acknowledgements}

The authors would like to acknowledge the financial support and scholarships to this research project given by Brazilian agencies: Coordenação de Aperfeiçoamento de Pessoal de Nível Superior (CAPES), Conselho Nacional de Desenvolvimento Científico e Tecnológico (CNPQ 479471/2012-6) and Fundação de Amparo à Ciência e Tecnologia do Estado de Pernambuco (FACEPE). 


\section{References}

1. Maeda S, Abe K, Yamamoto K, Tohyama O and Ito H. Active endoscope with SMA (shape memory alloy) coil springs. In: Proceeding of the 96th Micro Electro Mechanical Systems; 1996; San Diego, CA. San Diego: IEEE; 1996. p. 290-295.

2. Machado LG and Savi MA. Medical applications of shape memory alloys. Brazilian Journal of Medical and Biological Research. 2003; 36(6):683-691. http://dx.doi.org/10.1590/ S0100-879X2003000600001. PMid:12792695.

3. Araújo CJ and Gonzalez CH. Thermal alarm using a shape memory alloy helical spring. Proceeding of the 16th Brazilian Congress of Mechanical Engineering; 2001; Uberlândia, Brazil. 2001, p. 157:163.

4. Oliveira CAN, Gonzalez CH, Araújo CJ, Rocha JOS, Urtiga Filho SL and Quadros NF. Thermoelastic characterization of $\mathrm{Cu}-\mathrm{Zn}-\mathrm{Al}$ shape memory Alloy spring actuators. Proceedings of the 19th International Congress of Mechanical Engineering; 2007; Brasília, Brazil. 2007. p. 17:14.

5. Oliveira CAN, Gonzalez CH, de Araujo CJ, Araujo OO, Urtiga $\mathrm{SL}$. Thermoelastic properties on $\mathrm{Cu}-\mathrm{Zn}$-Al shape memory springs. Materials Research. 2011; 13(2):219-223.

6. Gonzalez CH, Oliveira CAN, Pina EAC, Urtiga SL, Araujo OO, Araujo CJ. Heat treatments and thermomechanical cycling influences on the R-Phase in Ti-Ni shape memory alloys. Materials Research. 2010; 13(3):325-331.

7. Shindo D, Murakami Y and Ohba T. Understanding precursor phenomena for the R-phase transformation in Ti-Ni-based alloys. MRS Bulletin. 2002; 27(2):121-127. http://dx.doi.org/10.1557/ mrs2002.48.

8. Paula ASC, Canejo JPHG, Martins RMS, Fernandes, FMB. Effect of thermal cyclin on the transformation temperature ranges of a Ni-Ti shape memory alloy. Materials Science and Engineering: A. 2004; 378(1-2):92-96.

9. Wang ZG, Zu XT, Fu P, Dai JY, Zhu S and Wang LM. Twoway shape memory effect of TiNi alloy coil extension springs. Materials Science and Engineering Structures. 2003; 360(12):126-131.

10. Somsen C, Zahres H, Kastner J, Wassermann EF, Kakeshita T and Saburi T. Influence of thermal annealing on the martensitic transitions in Ni-Ti shape memory alloys. Materials Science and Engineering Structures. 1999; 273-275:310-314.

11. Miyazaki S, Wayman CM. The shape memory mechanism associated with R-Phase transition in Ti-Ni Single-crystals. Acta Metallurgica. 1985; 36(1):181-192.

12. Otsuka K and Ren X. Physical metallurgy of Ti-Ni-based shape memory alloys. Progress in Materials Science. 2005; 50(5):511678. http://dx.doi.org/10.1016/j.pmatsci.2004.10.001

13. Sittner P, Landa M, Lukas $P$ and Novak V. R-phase transformation phenomena in thermomechanically loaded NiTi polycrystals. Mechanics of Materials. 2006; 38(5-6):475-492. http://dx.doi. org/10.1016/j.mechmat.2005.05.025.

14. Sittner P, Lugovyy D, Neov D, Landa M, Lukas P and Novak $\mathrm{V}$. On the R-phase transformation related phenomena in NiTi polycrystals subjected to thermomechanical loads. Journal de Physique. IV. 2004; 115:269-278. http://dx.doi.org/10.1051/ jp4:2004115032.

15. Nishida M and Honma T. All-round shape memory effect in Ni-Rich Tini alloys generated by constrained aging. Scripta Metallurgica et Materialia. 1984; 18(11):1293-1298. http:// dx.doi.org/10.1016/0036-9748(84)90125-X.
16. Liu Y and Mccormick PG. Influence of heat-treatment on the mechanical-behavior of a Niti alloy. ISIJ International. 1989; 29(5):417-422. http://dx.doi.org/10.2355/isijinternational.29.417.

17. Miyazaki S and Otsuka K. Deformation and transition behavior associated with the R-Phase in Ti-Ni alloys. Metallurgical Transactions. A, Physical Metallurgy and Materials Science. 1986; 17(1):53-63. http://dx.doi.org/10.1007/BF02644442.

18. Nishiyama Z, Fine ME, Meshii M, Wayman CM. Martensitic trasformation. Waltham: Academic Press; 1978.

19. Otubo J, Mei PR, Lima NBd, Serna MM, Gallego E. O efeito do tamanho de grão austenítico no número de orientações das variantes de martensita em ligas inoxidáveis com efeito de memória de forma. Rem: Revista Escola de Minas. 2007; 60(1):129-134.

20. Okita K, Okabe N, Sato T and Nakao T. Appearance of two-way strain in shape memory effect of Ti-Ni-Nb alloy - Influence of applied strain on two-way strain. Materials Transactions. 2006; 47(3):753-758. http://dx.doi.org/10.2320/matertrans.47.753.

21. Wang ZG, Zu XT, Dai JY, Fu P and Feng XD. Effect of thermomechanical training temperature on the two-way shape memory effect of TiNi and TiNiCu shape memory alloys springs. Materials Letters. 2003; 57(9-10):1501-1507. http://dx.doi. org/10.1016/S0167-577X(02)01014-5.

22. Norfleet DM, Sarosi PM, Manchiraju S, Wagner MFX, Uchic $\mathrm{MD}$, Anderson PM, et al. Transformation-induced plasticity during pseudoelastic deformation in Ni-Ti microcrystals. Acta Materialia. 2009; 57(12):3549-3561. http://dx.doi.org/10.1016/j. actamat.2009.04.009.

23. Lagoudas DC and Entchev PB. Modeling of transformationinduced plasticity and its effect on the behavior of porous shape memory alloys. Part I: constitutive model for fully dense SMAs. Mechanics of Materials. 2004; 36(9):865-892. http:// dx.doi.org/10.1016/j.mechmat.2003.08.006.

24. Chang CY, Vokoun D and Hu CT. Two-way shape memory effect of NiTi alloy induced by constraint aging treatment at room temperature. Metallurgical and Materials Transactions. A, Physical Metallurgy and Materials Science. 2001; 32(7):16291634. http://dx.doi.org/10.1007/s11661-001-0141-7.

25. Van Humbeeck J. Damping capacity of thermoelastic martensite in shape memory alloys. Journal of Alloys and Compounds. 2003; 355(1-2):58-64. http://dx.doi.org/10.1016/S09258388(03)00268-8.

26. Yoshida I, Ono T and Asai M. Internal friction of Ti-Ni alloys. Journal of Alloys and Compounds. 2000; 310(1-2):339-343. http://dx.doi.org/10.1016/S0925-8388(00)00957-9.

27. Yoshida I, Monma D, Ino K, Ono T, Otsuka K and Asai M. Internal friction of Ti-Ni-Cu ternary shape memory alloys, Mat Sci. Engineering Structures. 2004;(370):444-448.

28. Genlian Fan YZ, Otsuka K and Ren X. Ultrahigh damping in R-phase state of Ti-Ni-Fe alloy. Applied Physics Letters. 2006; 89:3.

29. INUNSMK Y. High damping capacity due to two-step phase transformation in Ni-Ti, Ni-Ti-Cu, and Fe-Cr-Mn alloys. Journal of Alloys and Compounds. 2003; 1(355):5.

30. Chang SH and Wu SK. Inherent internal friction of Ti51Ni39Cu10 shape memory alloy. Materials Transactions. 2007; 8(48):21432147.

31. Chang SH and Wu SK. Internal friction of R-phase and B19، martensite in equiatomic TiNi shape memory alloy under isothermal conditions. Journal of Alloys and Compounds. 2007; 437(1-2):120-126. http://dx.doi.org/10.1016/j.jallcom.2006.07.092. 